\title{
Health-Related Quality of Life during COVID-19 Pandemic: Assessing Impacts of Job Loss and Financial Support Programs in Japan
}

\author{
Takaaki Ikeda $^{1,2}$ (D) Ataru Igarashi ${ }^{3}$ (D) Satomi Odani $^{4}$ (D) \\ Masayasu Murakami ${ }^{1}$ (D) Takahiro Tabuchi $^{4}$
}

Received: 2 December 2020 / Accepted: 5 January 2021/Published online: 30 January 2021

(C) The International Society for Quality-of-Life Studies (ISQOLS) and Springer Nature B.V. 2021

\begin{abstract}
This cross-sectional study examined the association between job loss during the coronavirus disease 2019 (COVID-19) pandemic and health-related quality of life (HRQOL) in the Japanese working population and whether universal financial support program has a protective influence on the HRQOL. Two self-reported internet surveys were used to determine job loss during the pandemic: one was conducted between February and March 2020, just before the COVID-19 emergency declaration by the Japanese government (April 2020), and the other was conducted between August and September 2020. For the dependent variable, we used the EQ-5D-5L utility score (QOL utility score), which was assessed between August and September 2020. The independent variables were job loss after the state of emergency was declared and two types of government financial support (either universal support or support targeting childraising households). The Tobit regression model was applied, adjusting for covariates. Job loss during the pandemic was negatively associated with the QOL utility score in the fully adjusted model; the coefficient (95\% confidence interval [CI]) for job loss during the pandemic was -0.07 ( -0.11 to -0.03$)$. For the government financial support variables, the universal financial support program was associated with a better QOL utility score of the coefficient $(95 \% \mathrm{CI}), 0.05$ (0.03 to 0.08$)$. Job loss during the COVID-19 pandemic is negatively associated with HRQOL, while universal financial support is positively associated with HRQOL. Our study results imply that universal financial support during the COVID-19 era has a protective influence on an individual's HRQOL.
\end{abstract}

Keywords Allowance $\cdot$ Euro-QoL $\cdot$ EQ-5D $\cdot$ SARS-CoV-2 - Socioeconomic status · Subsidy

Takaaki Ikeda

t.ikeda0110@gmail.com

Extended author information available on the last page of the article 


\section{Introduction}

A novel coronavirus, called severe acute respiratory syndrome coronavirus-2 (SARSCoV-2,) was identified in December 2019. As a result, the entire world has been affected by the coronavirus 2019 (COVID-19) pandemic. Effective cures or vaccines are not in sufficient supply, and many countries have introduced restrictive measures to control the infection, including avoiding social interactions, banning international travel, and refraining from nonessential activities. These restrictive measures have been effective in reducing the incidence of COVID-19 (Islam et al. 2020; Kucharski et al. 2020); however, there have been negative impacts on social and economic activities (Hensher 2020; Kawohl and Nordt 2020; Pieh et al. 2020; Twenge and Joiner 2020) with over 1 billion jobs lost globally (Luca Ventura 2020).

The World Health Organization declared COVID-19 a pandemic on March 11, 2020. In Japan, a nationwide state of emergency was declared on April 16, 2020, and the government requested individuals to refrain from performing nonessential activities and maintain physical distancing. Japan's state of emergency was lifted on May 31, 2020. As of this writing (December 19, 2020), the state of emergency has not been reimposed in Japan; the country has recorded 192,418 COVID-19 cases and 2827 deaths, which is far lower than those in other Western countries (Ministry of Health, Labour, and Welfare 2020).

However, during the "COVID-19 era," Japan has been hit with an economic decline, as have other countries worldwide. By April 2020, approximately 300,000 jobs had been lost compared with those lost in January 2020, with the unemployment rate rising from $2.4 \%$ in January to $3.0 \%$ in April (Ministry of Internal Affairs and Communications 2020).

To assist Japanese citizens, the government implemented several additional financial support programs: (1) the Special Cash Payment program provided a one-time payment of 100,000 yen (100 yen roughly equals one US dollar) to every resident registered with the Basic Resident Registration System as of April 27, 2020; (2) Temporary Special Benefit for Child-raising Households offered a one-time payment of 10,000 yen for each eligible child; (3) Subsidy Program for Sustaining Business offered up to 2 million yen for corporations and 1 million yen for sole proprietors, including freelancers, who had seen their earnings drop due to the outbreak; and (4) Employment Adjustment Subsidy was provided so that employers who were forced to curtail their business activities due to the effects of the pandemic could keep their staff members employed.

The Special Cash Payment is a universal financial support program provided to every resident regardless of financial status. The Temporary Special Benefit for Childraising Households provides a one-time payment benefit of 10,000 yen for each eligible child born from April 2, 2005, to March 31, 2020 (children under the third grade of junior high school in 2020). The Subsidy Program for Sustaining Business and Employment Adjustment Subsidy programs are for employers or freelancers rather than for individuals.

Economic recessions can affect an individuals' overall health. A recent study described negative health effects during the economic recession of 2008-2009, including poor self-rated health, psychological distress, and mortality (Margerison-Zilko et al. 2016). Recession also reduces an individuals' use of health care (Madureira-Lima et al. 
2018; McInerney and Mellor 2012; Sánchez-Recio et al. 2020). Although it could be hypothesized that job loss during the COVID-19 pandemic is also accompanied by a self-perceived health decline, or health-related quality of life (HRQOL), in the working population, no studies have demonstrated this possibility. Besides, it is not certain whether financial support has a protective effect on HRQOL. Therefore, this crosssectional study examines the data on employment status before and after Japan's state of emergency was declared, types of government financial supports (targeted or universal), and the influence of different types of support on HRQOL.

\section{Methods}

\section{Data}

To determine job loss before and after Japan's emergency declaration, we used data from two prospective cohort studies: the Japan Society and New Tobacco Internet Survey (JASTIS) and the Japan COVID-19 and the Society Internet Survey (JACSIS). JASTIS was an internet survey focusing on the socioeconomic factors and use of heated tobacco products in Japan (Tabuchi et al. 2017, 2019). JACSIS (internet survey) was designed to investigate the social and health situation related to the COVID-19 pandemic.

The JASTIS survey was conducted between February and March 2020, just before the emergency declaration by the Japanese government; the JACSIS survey was conducted between August and September 2020 (Supplementary Fig. 1). Participants were enrolled into a self-reported internet survey managed by a nationwide internet research agency, Rakuten Insight; the national, 2.3-million person pool encompassed a range of demographic characteristics: occupation, education level achieved, income level, and marital status (Tabuchi et al. 2017, 2019). Participants in both JASTIS and JACSIS were recruited via an e-mail invitation from individuals who had been registered with Rakuten Insight. Candidates were invited to enroll in the study after being randomly selected from approximately 2.3 million participants using a computer algorithm; the selected participants were consistent with the Japanese demographic composition. Candidates responded to the web-based questionnaire if they agreed to provide web-based informed consent and intended to participate both in JASTIS and JACSIS. Eleven thousand participants were invited and responded to the JASTIS survey, and 8686 participants completed the JACSIS survey (79.0\%, Supplementary Fig. 1).

To validate data quality, we excluded respondents who had discrepancies or unusual responses (Tabuchi et al. 2017, 2019), e.g., selecting "all" in questions listing drugs used or chronic diseases ( $n=629$, remaining $n=7994)$.

\section{Variables}

For the dependent variable, we used the EuroQol 5-dimension 5-level (EQ-5D-5L), which is an internationally developed HRQOL questionnaire, used in previous studies (Devlin et al. 2020). In the present study, this dependent variable was only assessed at follow-up. This index comprises five items on a 1-to-5 scale (no problems to extreme 
problems): mobility, self-care, usual activities, pain/discomfort, and anxiety/depression. Each health state is defined by one QOL "utility" 0-to-1 score (death to full health), which can be transformed by using the interim scoring for the Japanese EQ-5D-5L (Ikeda et al. 2015).

We used three independent variables: (1) job loss that occurred after the Japanese government declared a state of emergency, (2) universal financial support programs from the government (the Special Cash Payment), and (3) financial support for families with children (the Temporary Special Benefit for Child-raising Households). The detailed information for each type of government financial support has been previously summarized in the Introduction section. Job loss was determined if participants answered "unemployed" to the question regarding the current job situation or answered "yes" to the question "job loss because of the COVID-19 issue (including nonrenewal of contract or other conditions)."

\section{Control Variables}

Control variables, which were assessed before Japan's emergency declaration, were as follows: age, gender, education level achieved, equivalized household income (annual household divided by the square root of the number of household members), occupation (manager, self-employed, permanent worker other than manager, non-permanent worker, or internal worker), health care insurance type (Employee Health Insurance or National Health Insurance), and presence of morbidities (hypertension, diabetes, cancer, angina, asthma, chronic obstructive pulmonary disease, bronchitis/pneumonia, periodontal disease, caries, chronic pain, depression, or psychological disorder other than depression). Further, we considered the following control variables based on the survey conducted after the emergency declaration: onset of morbidity (previously mentioned morbidity) and changes in the equivalized household income from the time of pre-declaration survey and to the post-declaration survey.

\section{Statistical Analyses}

Although no missing variables were observed in both independent and dependent variables, $0.2 \%-28.8 \%$ of the nine control variables were missing (Supplementary Table 1). As a result, we first imputed these missing variables using the random forest imputation procedure, which has been recommended for data with mixed continuous and categorical variables (Stekhoven and Bühlmann 2012). Incomplete variables were imputed as factors with missing variables not greater than $30 \%$ as explanatory variables (Stekhoven and Bühlmann 2012).

After the imputation procedure, we excluded participants not meeting the following criteria in the survey conducted before the declaration: (1) age less than 18 years and over 60 years $(n=2278)$, (2) public assistance recipients $(n=1)$, (3) non-insurer $(n=$ $36)$, (4) retired $(n=7),(5)$ students $(n=679),(6)$ domestic workers $(n=491)$, and (7) unemployed $(n=325)$. The final analysis had 4177 respondents. After conducting descriptive analysis, we constructed regression models to examine the associations of job loss during the pandemic and government financial support variables with the QOL utility score, as calculated using EQ-5D-5L.

In our data, QOL utility scores had a ceiling effect with $56.3 \%$ of respondents reporting full health. To detect appropriate models for the censored outcome, we 
compared model fit between ordinary least square (OLS) and Tobit using models with no control variables. For model fit, the root mean squared error (RMSE) in the OLS model and sigma in the Tobit model were calculated (Austin 2002; Austin et al. 2000). Coefficients calculated by the Tobit model can be interpreted in a similar manner to those calculated by the OLS model; however, the linear effect is on the uncensored latent variable, not the observed outcome (Austin 2002; Austin et al. 2000).

First, we constructed a univariate regression model in which job loss and financial support variables (i.e., Special Cash Payment and Temporary Special Benefit for Childraising Households) were separately included in the regression model (Model 1). Second, all variables assessed before the declaration (e.g., gender, age, socioeconomic status) were added in addition to three independent variables (multivariate regression model, Model 2). Third, the onset of morbidities and change in the equivalized household income between the time before and after the declaration were added to Model 2 (multivariate regression model, Model 3).

All analyses, other than the random forest imputation were conducted using Stata, version 16.0 (StataCorp LLC, College Station, Texas, US). Random forest imputation was conducted using Python, version 3.8.3.

\section{Results}

Tables 1 and 2 show demographic characteristics, job loss during the pandemic, and government financial support variables with QOL utility scores calculated using EQ5D-5L; those respondents who did not experience or did experience job loss were 0.92 (standard deviation $[\mathrm{SD}]=0.12)$ and $0.83(\mathrm{SD}=0.18)$, respectively (also see Supplementary Figs. 2 and 3). 3.5\% of the respondents reported that they experienced job loss during the declaration. The proportion of respondents who received Special Cash Payment and Temporary Special Benefit for Child-raising Households were $89.4 \%$ and $11.0 \%$, respectively. Those respondents who received the Special Cash Payment were more likely to have better QOL utility scores (Table 2); the score was more likely to be lower in men gender, in those with lower socioeconomic status, or in those having a morbidity before the declaration. Table 3 presents job loss after the declaration and responses to each EQ-5D-5L question. Overall, respondents who experienced job loss during the pandemic were more likely to choose adverse responses in each domain. This trend was particularly observed for pain/discomfort and anxiety/ depression domains.

The RMSE in the OLS model and sigma in the Tobit model were 0.13 and 0.06 , respectively, indicating that the Tobit model is more accurate than the OLS model. Therefore, we used the Tobit model for subsequent analyses. Table 4 presents the results of the Tobit models. Job loss during the pandemic was negatively associated with the QOL utility score, adjusting for characteristics before the declaration of the coefficient (95\% confidence interval [CI], -0.11 [ -0.15 to -0.07$]$ ) (Model 2).

This association was attenuated but remained significant when additional control variables were added to Model 2 (Model 3): the coefficient (95\% CI) for job loss during the pandemic was -0.07 ( -0.11 to -0.03 ). These results suggest that the QOL utility score was 0.07 lower in those respondents who lost their jobs during the declaration compared with those who did not. The results of the associations between government 
Table 1 Characteristics before the declaration and quality of life utility score $(n=4177)$

\begin{tabular}{|c|c|c|c|c|}
\hline & \multirow[t]{2}{*}{ Total number of respondents } & \multicolumn{3}{|c|}{ Quality of life utility score } \\
\hline & & Mean & $\mathrm{SD}$ & 25 th- 75 th percentile \\
\hline \multicolumn{5}{|l|}{ Age group (years) } \\
\hline $18-30$ & 865 & 0.91 & 0.16 & $0.85-1.00$ \\
\hline $31-40$ & 858 & 0.92 & 0.13 & $0.87-1.00$ \\
\hline $41-46$ & 785 & 0.92 & 0.11 & $0.87-1.00$ \\
\hline $47-53$ & 889 & 0.92 & 0.12 & $0.83-1.00$ \\
\hline $54-59$ & 780 & 0.92 & 0.10 & $0.87-1.00$ \\
\hline \multicolumn{5}{|l|}{ Gender } \\
\hline Men & 2639 & 0.92 & 0.13 & $0.87-1.00$ \\
\hline Women & 1538 & 0.91 & 0.12 & $0.83-1.00$ \\
\hline \multicolumn{5}{|c|}{ Highest education level (years) } \\
\hline$\leq 9$ & 29 & 0.79 & 0.23 & $0.69-1.00$ \\
\hline $10-12$ & 873 & 0.91 & 0.13 & $0.82-1.00$ \\
\hline$\geq 13$ & 3275 & 0.92 & 0.12 & $0.87-1.00$ \\
\hline \multicolumn{5}{|c|}{ Quintile of income level } \\
\hline 1st (lowest) & 903 & 0.88 & 0.16 & $0.82-1.00$ \\
\hline 2nd & 809 & 0.92 & 0.12 & $0.87-1.00$ \\
\hline $3 \mathrm{rd}$ & 801 & 0.92 & 0.12 & $0.87-1.00$ \\
\hline 4 th & 858 & 0.93 & 0.11 & $0.87-1.00$ \\
\hline 5th (highest) & 806 & 0.93 & 0.11 & $0.87-1.00$ \\
\hline \multicolumn{5}{|l|}{ Occupation } \\
\hline Manager & 168 & 0.91 & 0.17 & $0.83-1.00$ \\
\hline Permanent & 2814 & 0.92 & 0.12 & $0.87-1.00$ \\
\hline Self-owned & 334 & 0.89 & 0.15 & $0.82-1.00$ \\
\hline Non-permanent & 835 & 0.90 & 0.12 & $0.83-1.00$ \\
\hline Internal & 26 & 0.84 & 0.13 & $0.76-1.00$ \\
\hline \multicolumn{5}{|l|}{ Hypertension } \\
\hline No & 3668 & 0.92 & 0.12 & $0.87-1.00$ \\
\hline Yes & 509 & 0.88 & 0.16 & $0.82-1.00$ \\
\hline \multicolumn{5}{|l|}{ Diabetes } \\
\hline No & 3652 & 0.92 & 0.12 & $0.87-1.00$ \\
\hline Yes & 525 & 0.89 & 0.17 & $0.82-1.00$ \\
\hline \multicolumn{5}{|l|}{ Cancer } \\
\hline No & 3771 & 0.92 & 0.12 & $0.87-1.00$ \\
\hline Yes & 406 & 0.88 & 0.17 & $0.82-1.00$ \\
\hline \multicolumn{5}{|l|}{ Angina } \\
\hline No & 4108 & 0.92 & 0.12 & $0.87-1.00$ \\
\hline Yes & 69 & 0.78 & 0.25 & $0.85-1.00$ \\
\hline \multicolumn{5}{|c|}{ Chronic obstructive pulmonary disease } \\
\hline No & 3796 & 0.92 & 0.12 & $0.87-1.00$ \\
\hline Yes & 381 & 0.88 & 0.17 & $0.82-1.00$ \\
\hline
\end{tabular}


Table 1 (continued)

\begin{tabular}{lllll}
\hline & Total number of respondents & \multicolumn{3}{l}{ Quality of life utility score } \\
\cline { 3 - 5 } & & Mean & SD & 25th-75th percentile \\
\cline { 3 - 5 } & & & & \\
Bronchitis/pneumonia & & 0.92 & 0.12 & $0.87-1.00$ \\
No & 4061 & 0.79 & 0.24 & $0.83-1.00$ \\
Yes & 116 & & & \\
Asthma & & 0.92 & 0.12 & $0.87-1.00$ \\
No & 3959 & 0.86 & 0.19 & $0.82-1.00$ \\
Yes & 218 & & & \\
Periodontal disease & & 0.92 & 0.12 & $0.87-1.00$ \\
No & 3733 & 0.87 & 0.16 & $0.82-1.00$ \\
Yes & 444 & & & \\
Caries & & 0.92 & 0.12 & $0.87-1.00$ \\
No & 3785 & 0.87 & 0.16 & $0.82-1.00$ \\
Yes & 392 & & & \\
Chronic pain & & 0.92 & 0.12 & $0.87-1.00$ \\
No & 4096 & 0.75 & 0.25 & $0.82-1.00$ \\
Yes & 81 & & & \\
Psychological disorder other than depression & 3657 & 0.92 & 0.12 & $0.87-1.00$ \\
No & 520 & 0.86 & 0.17 & $0.81-1.00$ \\
Yes & & &
\end{tabular}

Depression before the declaration was omitted as none of the respondents answered "yes" to the question

financial support variables and the QOL utility scores are also shown in Table 3 (Model 3); the Special Cash Payment was associated with better QOL utility score of the coefficient (95\% CI): 0.05 (0.03 to 0.08). Meanwhile, the Temporary Special Benefit for Child-raising Households was not associated with the QOL utility score.

We showed that a poor QOL utility score in the fully adjusted model was associated with low educational attainment and a low income level: the coefficients (95\% CI) were $-0.16(-0.24$ to -0.08$)$ and -0.07 ( -0.10 to -0.05$)$, respectively (Table 4$)$. The onset of several morbidities (depression, hypertension, caries, and chronic pain) was also associated with poor HRQOL: the coefficients of depression, $-0.16(-0.20$ to -0.13$)$; hypertension, -0.05 ( -0.09 to -0.01$)$; caries, -0.04 ( -0.07 to -0.01$)$; and chronic pain, $-0.15(-0.17$ to -0.12$)$.

\section{Discussion}

This study examined the association between job loss during the COVID-19 pandemic with HRQOL in the working population in Japan. We showed that respondents who experienced job loss had a poor HRQOL. Further, we also found that universal financial support had a positive effect on an individual's HRQOL. 
Table 2 Characteristics after the emergency declaration and quality of life utility score $(n=4177)$

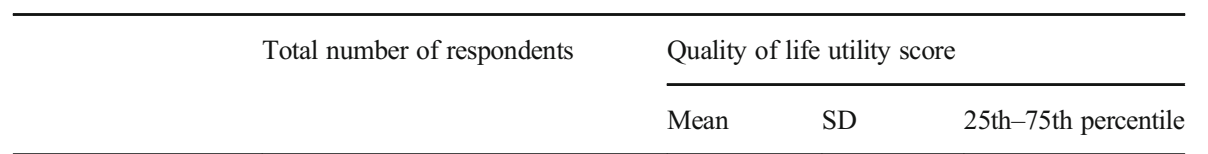

Job loss during the pandemic

$\begin{array}{lllll}\text { No } & 4031 & 0.92 & 0.12 & 0.87-1.00 \\ \text { Yes } & 146 & 0.83 & 0.18 & 0.78-1.00\end{array}$

Special Cash Payment

$\begin{array}{ll}\text { Not received } & 442 \\ \text { Received } & 3735\end{array}$

$\begin{array}{lll}0.87 & 0.23 & 0.81-1.00 \\ 0.92 & 0.11 & 0.87-1.00\end{array}$

Temporary Special Benefit for Child-raising Households

$\begin{array}{lllll}\text { Not received } & 3718 & 0.92 & 0.13 & 0.87-1.00 \\ \text { Received } & 459 & 0.91 & 0.12 & 0.87-1.00\end{array}$

Onset of hypertension

$\begin{array}{ll}\text { No } & 4046 \\ \text { Yes } & 131\end{array}$

4046

0.92

$0.13 \quad 0.87-1.00$

Onset of diabetes

$\begin{array}{ll}\text { No } & 4133 \\ \text { Yes } & 44\end{array}$

4133
44

0.92

0.14

$0.82-1.00$

Onset of cancer

$\begin{array}{ll}\text { No } & 4158 \\ \text { Yes } & 19\end{array}$

0.92

$0.12 \quad 0.87-1.00$

Onset of angina

$\begin{array}{ll}\text { No } & 4153 \\ \text { Yes } & 24\end{array}$

$\begin{array}{lll}0.92 & 0.12 & 0.87-1.00 \\ 0.74 & 0.28 & 0.55-1.00\end{array}$

Onset of chronic obstructive pulmonary disease

$\begin{array}{ll}\text { No } & 4153 \\ \text { Yes } & 24\end{array}$

$\begin{array}{lll}0.92 & 0.12 & 0.87-1.00 \\ 0.78 & 0.23 & 0.56-1.00\end{array}$

Onset of bronchitis/pneumonia

$\begin{array}{ll}\text { No } & 4139 \\ \text { Yes } & 38\end{array}$

0.92

$0.12 \quad 0.87-1.00$

Onset of periodontal disease

$\begin{array}{ll}\text { No } & 3995 \\ \text { Yes } & 182\end{array}$

0.84

$0.21 \quad 0.72-1.00$

Onset of caries

$\begin{array}{ll}\text { No } & 3936 \\ \text { Yes } & 241\end{array}$

0.92

0.13

0.87-1.00

0.89

0.13

0.82-1.00

Onset of chronic pain

$\begin{array}{ll}\text { No } & 3850 \\ \text { Yes } & 327\end{array}$

0.92

$0.13 \quad 0.87-1.00$

0.89

0.13

$0.82-1.00$

Onset of depression

$\begin{array}{ll}\text { No } & 3976 \\ \text { Yes } & 201\end{array}$

$\begin{array}{lll}0.92 & 0.12 & 0.87-1.00 \\ 0.84 & 0.13 & 0.78-1.00 \\ 0.92 & 0.12 & 0.87-1.00 \\ 0.76 & 0.18 & 0.68-1.00\end{array}$


Table 2 (continued)

\begin{tabular}{|c|c|c|c|c|}
\hline & \multirow[t]{2}{*}{ Total number of respondents } & \multicolumn{3}{|c|}{ Quality of life utility score } \\
\hline & & Mean & $\mathrm{SD}$ & 25 th -75 th percentile \\
\hline \multicolumn{5}{|c|}{ Onset of psychological disorder other than depression } \\
\hline No & 4114 & 0.92 & 0.13 & $0.87-1.00$ \\
\hline Yes & 63 & 0.84 & 0.15 & $0.78-1.00$ \\
\hline
\end{tabular}

Onset of asthma was omitted as none of the respondents answered "yes" to the question

To date, two cross-sectional studies from Sweden and Japan have reported that job loss is associated with a poor HRQOL (measured by EQ-5D-5L); these findings are in line with those of our study (Fujikawa et al. 2011; Norström et al. 2019). However, because the earlier studies had cross-sectional designs, they did not consider whether job loss caused by mental health disorders or onset of disability could result in a reverse association. However, in our study, we assessed health status before the emergency declaration, socioeconomic conditions, and changes in conditions before and after the declaration. Moreover, job loss resulting from the COVID-19 pandemic is exogenous; thus, the present study has found that job loss leads to poor HRQOL (Albuquerque et al. 2020).

Table 3 Unemployment status at follow-up and responses to each EQ-5D-5L question $(n=4177)$

\begin{tabular}{|c|c|c|c|c|c|c|c|c|c|c|}
\hline & \multicolumn{10}{|c|}{5 level items in each question } \\
\hline & \multicolumn{2}{|c|}{$\begin{array}{l}1 \text { (no } \\
\text { problems) }\end{array}$} & \multicolumn{2}{|c|}{$\begin{array}{l}2 \text { (slight } \\
\text { problems) }\end{array}$} & \multicolumn{2}{|c|}{$\begin{array}{l}3 \text { (moderate } \\
\text { problems) }\end{array}$} & \multicolumn{2}{|c|}{$\begin{array}{l}4 \text { (severe } \\
\text { problems) }\end{array}$} & \multicolumn{2}{|c|}{$\begin{array}{l}5 \text { (unable to/ } \\
\text { extreme prob- } \\
\text { lems) }\end{array}$} \\
\hline & $\mathrm{N}$ & $\%$ & $\mathrm{~N}$ & $\%$ & $\mathrm{~N}$ & $\%$ & $\mathrm{~N}$ & $\%$ & $\mathrm{~N}$ & $\%$ \\
\hline \multicolumn{11}{|l|}{ Mobility } \\
\hline Did not experience job loss & 3813 & 94.6 & 144 & 3.6 & 34 & 0.8 & 20 & 0.5 & 20 & 0.5 \\
\hline Experienced job loss & 120 & 82.2 & 11 & 7.5 & 8 & 5.5 & 4 & 2.7 & 3 & 2.1 \\
\hline \multicolumn{11}{|l|}{ Self-care } \\
\hline Did not experience job loss & 3913 & 97.1 & 60 & 1.5 & 29 & 0.7 & 13 & 0.3 & 16 & 0.4 \\
\hline Experienced job loss & 127 & 87.0 & 7 & 4.8 & 6 & 4.1 & 5 & 3.4 & 1 & 0.7 \\
\hline \multicolumn{11}{|l|}{ Usual activities } \\
\hline Did not experience job loss & 3811 & 94.5 & 139 & 3.5 & 49 & 1.2 & 13 & 0.3 & 19 & 0.5 \\
\hline Experienced job loss & 118 & 80.8 & 11 & 7.5 & 10 & 6.9 & 4 & 2.7 & 3 & 2.1 \\
\hline \multicolumn{11}{|l|}{ Pain/discomfort } \\
\hline Did not experience job loss & 2780 & 69.0 & 978 & 24.3 & 201 & 5.0 & 52 & 0.3 & 20 & 0.5 \\
\hline Experienced job loss & 82 & 56.2 & 47 & 32.2 & 11 & 7.5 & 5 & 3.4 & 1 & 0.7 \\
\hline \multicolumn{11}{|l|}{ Anxiety/depression } \\
\hline Did not experience job loss & 2871 & 71.2 & 803 & 19.9 & 220 & 5.5 & 83 & 2.1 & 54 & 1.3 \\
\hline Experienced job loss & 60 & 41.1 & 54 & 37.0 & 18 & 12.3 & 8 & 5.5 & 6 & 4.1 \\
\hline
\end{tabular}




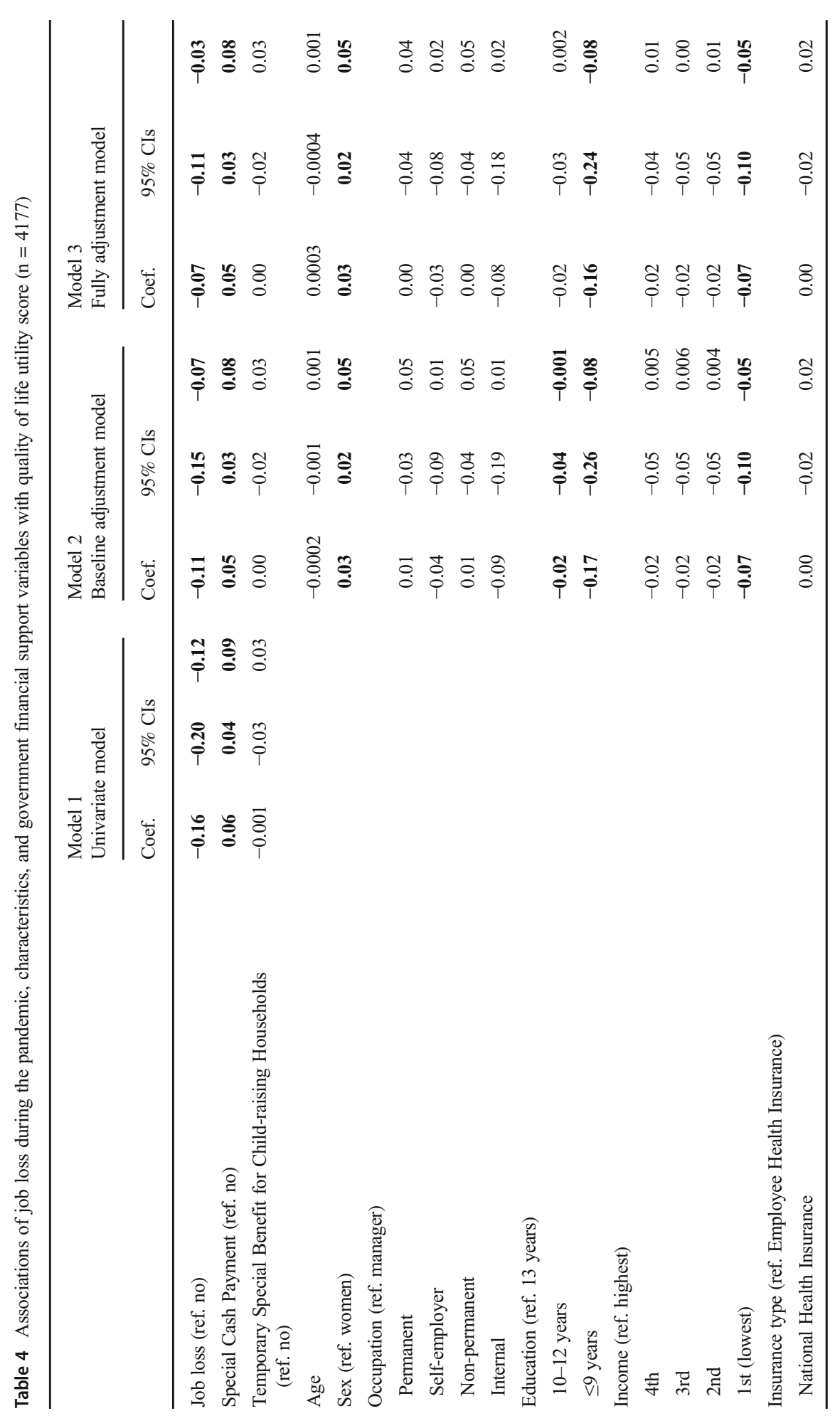




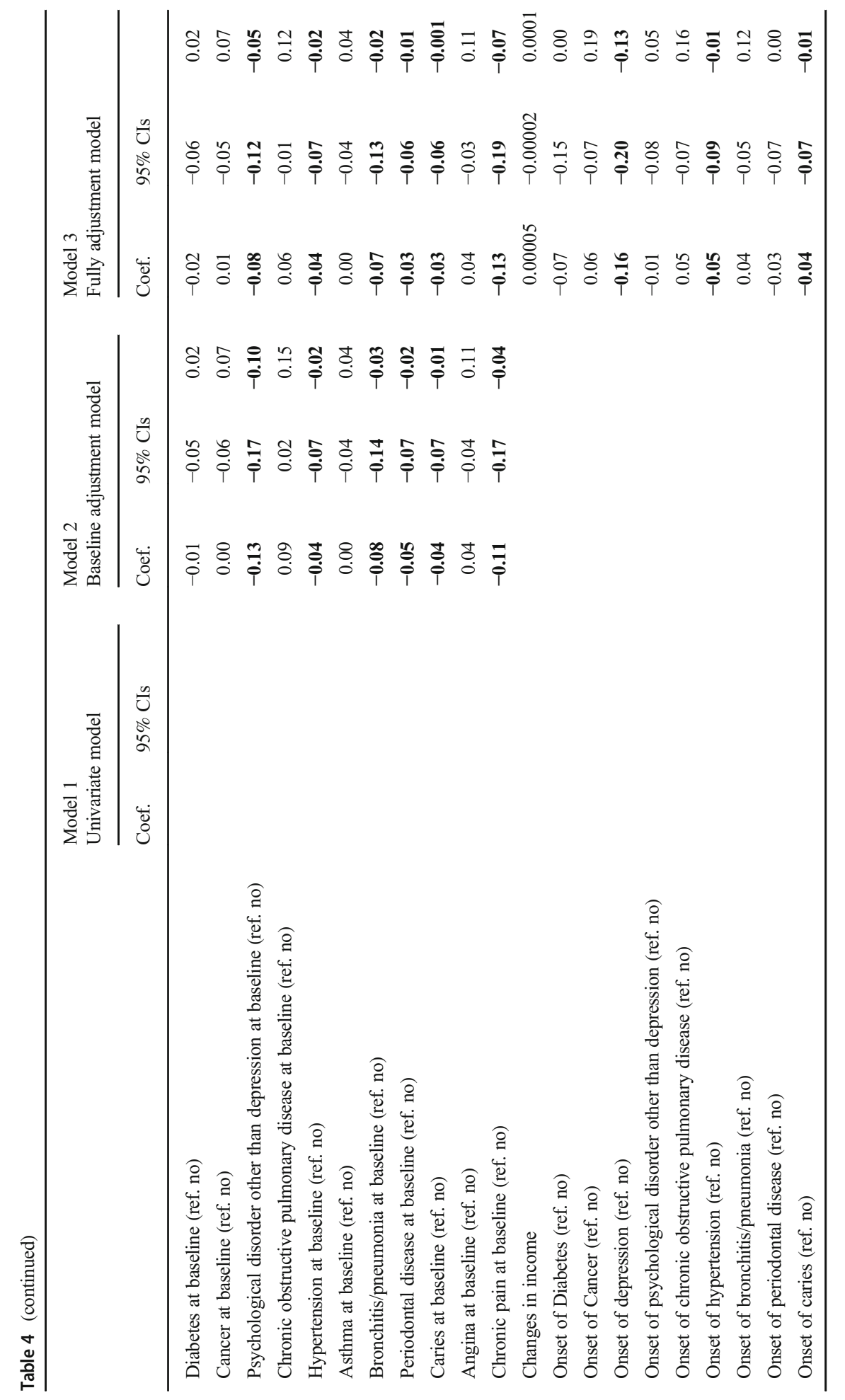




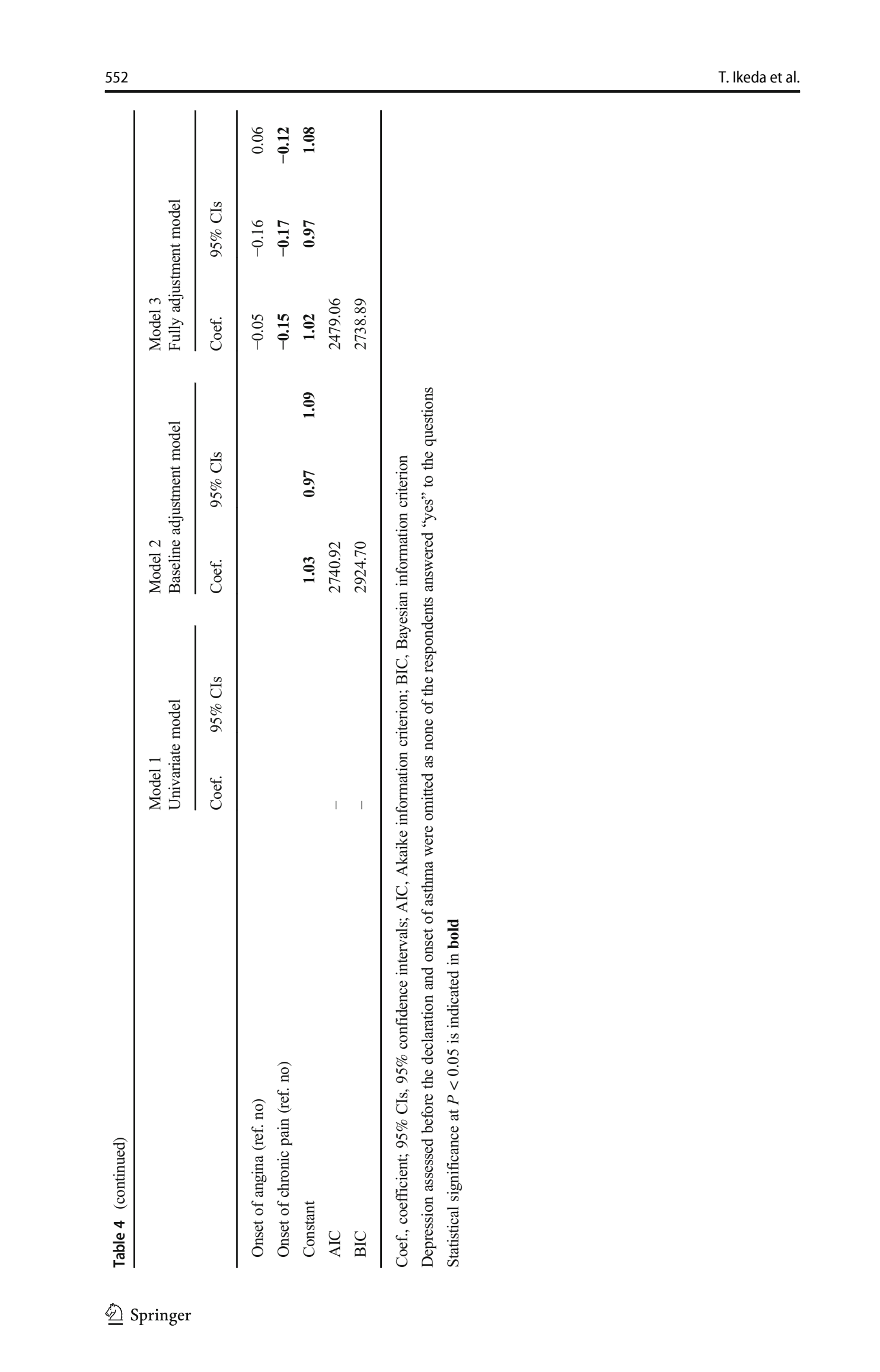


The Special Cash Payment might have a protective influence on HRQOL; as mentioned in the Introduction section, this payment is 100,000 yen of the universal financial support that is not reduced by income level. According to national data from Japan, the household savings rate for the April-June period of 2020 was $23.1 \%$, the highest rate since 1994 (Economic and Social Research Institute 2020). This result suggests that the Special Cash Payment had a positive influence on an individual's HRQOL, even if they placed the payment into savings.

Although this was a universal financial support program, approximately $10 \%$ of the respondents answered that they did not receive support. Therefore, future studies are warranted to clarify the characteristics and determine how to provide support to these people. On the other hand, the Temporary Special Benefit for Child-raising Households was not associated with HRQOL. This discrepancy might be explained by the following reasons: the amount of financial support was totally different and the amount of the Special Cash Payment was larger than that of the Temporary Special Benefit for Childraising Households.

In Japan, 100,000 yen is equivalent to $47.6 \%$ of the median monthly wage for individuals 20-24 years old and to $26.1 \%$ of those who are 55-59 years old (Ministry of Health, Labour, and Welfare 2019). The two types of financial support were different: the Special Cash Payment was a universal support program, whereas the Temporary Special Benefit for Child-raising Households was only given to families who had children. Although further studies are warranted, our data suggest that providing universal financial support may improve HRQOL in the working population.

We found that groups with lower socioeconomic status (education and income) had poorer HRQOL scores. Similar to our study, many previous studies have reported that lower educational attainment and lower-income levels are associated with poorer HRQOL scores (Fujikawa et al. 2011; Janssen et al. 2019; Yang et al. 2018). In the current study, a change in the income level was not associated with HRQOL. Previous studies before the COVID-19 era have reported that a change in income level is not associated with changes in health status (Adams et al. 2003; Smith 2005); these findings imply that health has an adverse effect on income, rather than vice versa.

In the current study, the health of $1 \%-8 \%$ of respondents deteriorated after the state of emergency was declared. Hence, additional support programs may be important as further unemployment and loss of income are expected in the future (Luca Ventura 2020). We also found that men gender was associated with better QOL utility scores compared with the women gender. This result is in line with that of a recent systematic review that investigated the impact of the COVID-19 pandemic on mental health in the general population (Xiong et al. 2020). Therefore, tackling gender inequalities might be essential during the COVID-19 era.

The possible mechanisms underlying the association between job loss and poor HRQOL could be due to a worsening in mental health and somatic symptoms. Our study saw that an increase in depression, caries, and chronic pain was associated with poor HRQOLs and that the association of job loss with HRQOL decreased when these variables were added. Moreover, respondents who experienced job loss during the pandemic were more likely to choose adverse responses in the pain/discomfort and anxiety/depression domains (Table 3).

The increase in morbidity has been observed in earlier studies; the 2008-2009 recession led to a reduction in health visits (Madureira-Lima et al. 2018; McInerney 
and Mellor 2012; Sánchez-Recio et al. 2020), even if the visit might be essential for an individual (Czeisler et al. 2020). A recent cross-sectional study from Bangladesh targeted university students and found that COVID-19 induced fear and depression was significantly associated with career anxiety of this future workforce (Mahmud et al. 2020). Thus, the fear of COVID-19 itself possibly impacts on an individual's HRQOL.

As stated earlier, the COVID-19 pandemic has had a large impact on individuals' careers. Although the pandemic is difficult to control and adds to global uncertainty, career competency and resilience might play an important role in mitigating the career shock caused by the pandemic (Akkermans et al. 2020; Hite and McDonald 2020). After the Japanese state of emergency was declared on April 16, 2020, another concern was a decrease in healthy physical and social routines such as walking (Tison et al. 2020) and common social interactions (Banerjee and Rai 2020). Hence, establishing multifaceted prevention strategies are essential to tackle adverse health impacts resulting from pandemic restrictions.

This study has both strengths and limitations. One strength was the timing of the surveys, which allowed the demonstration of the influence of the COVID-19 pandemic, with the baseline survey that was conducted 1 month before the declaration, and the follow-up survey conducted 4 months after the declaration. We used internet survey data, possibly reducing the influence of recall bias, but an internet survey might be particularly effective during the COVID-19 period. In addition, we had socioeconomic status and health data before the declaration, adjusted in the regression model; thus, we considered possible confounders.

Our study has several limitations. First, we could not examine the QOL utility scores due to a lack of baseline information; however, job loss resulting from the COVID-19 pandemic is exogenous, and studies have found that job loss leads to poor HRQOL (Albuquerque et al. 2020). Second, some of our study results might not be applicable to other countries; the influence of universal financial support on HRQOL might be different depending on the amount.

By far, the Japanese government has not introduced additional "lockdown measures" that have been imposed in other countries; the Japanese government asked people to refrain from nonessential activities and maintain a healthy physical distance without penalties. Thus, the influence of the economic impact as a result of the declaration in Japan would be different than in other countries. Indeed, the unemployment rate in Japan as of April 2020 (3.0\%) was lower than that of other countries at the same time (e.g., United States with a 14.3\% rate [Australian Bureau of Statistics 2020; US Bureau of Labor Statistics 2020]). Third, our results might be influenced by selection bias because we used internet survey data, indicating that individuals who did not have smartphone or access to internet might not be covered in our analysis.

\section{Conclusions}

Job loss during the COVID-19 pandemic is negatively associated with HRQOL, whereas universal financial support program is positively associated with HRQOL. Although the impact of job loss on HRQOL is enormous, universal financial support program might have a positive impact on a larger number of residents. 
Supplementary Information The online version contains supplementary material available at https://doi.org/ 10.1007/s11482-021-09918-6.

Funding This study was funded by the Japan Society for the Promotion of Science (JSPS) KAKENHI Grants [grant number 17H03589;19 K10671;19 K10446;18H03107; 18H03062; 19 K19818], the JSPS Grant-in-Aid for Young Scientists [grant number 19 K19439], Research Support Program to Apply the Wisdom of the University to tackle COVID-19 Related Emergency Problems, University of Tsukuba, a Health Labour Sciences Research Grant [grant number 19FA1005;19FG2001], and the Taiju Life Social Welfare Foundation. The views and opinions expressed in this article are those of the authors and do not necessarily reflect the official policy or position of the respective funding organizations.

Data Availability The data used in this study are not available in a public repository because they contain personally identifiable or potentially sensitive patient information. Based on the regulations for ethical guidelines in Japan, the Research Ethics Committee of the Osaka International Cancer Institute has imposed restrictions on the dissemination of the data collected in this study. All data enquiries should be addressed to the person responsible for data management, Dr. Takahiro Tabuchi at the following e-mail address: tabuchitak@gmail.com.

\section{Declarations}

Ethical Approval This study was reviewed and approved by the Research Ethics Committee of the Osaka International Cancer Institute (no. 20084).

Consent to Participate All participants provided web-based informed consent before responding to the online questionnaire. A credit point known as "Epoints," which could be used for internet shopping and cash conversion, was provided to the participants as an incentive.

\section{Competing Interests None}

\section{References}

Adams, P., Hurd, M. D., McFadden, D., Merrill, A., \& Ribeiro, T. (2003). Healthy, wealthy, and wise? Tests for direct causal paths between health and socioeconomic status. Journal of Econometrics, 112(1), 3-56. https://doi.org/10.1016/S0304-4076(02)00145-8.

Akkermans, J., Richardson, J., \& Kraimer, M. L. (2020). The Covid-19 crisis as a career shock: Implications for careers and vocational behavior. Journal of Vocational Behavior, 119, 103434. https://doi.org/10. 1016/j.jvb.2020.103434.

Albuquerque, R., Koskinen, Y., Yang, S., \& Zhang, C. (2020). Resiliency of Environmental and Social Stocks: An Analysis of the Exogenous COVID-19 Market Crash. The Review of Corporate Finance Studies, 9, 593-621. https://doi.org/10.1093/rcfs/cfaa011.

Austin, P. C. (2002). A comparison of methods for analyzing health-related quality-of-life measures. Value in Health, 5(4), 329-337. https://doi.org/10.1046/j.1524-4733.2002.54128.x.

Austin, P. C., Escobar, M., \& Kopec, J. A. (2000). The use of the Tobit model for analyzing measures of health status. Quality of Life Research, 9(8), 901-910. https://doi.org/10.1023/A:1008938326604.

Australian Bureau of Statistics. (2020). Understanding unemployment and the loss of work during the COVID-19 period: An Australian and International perspective. https:/www.abs.gov.au/articles/ understanding-unemployment-and-loss-work-during-covid-19-period-australian-and-internationalperspective. Accessed 24 October 2020.

Banerjee, D., \& Rai, M. (2020). Social isolation in Covid-19: The impact of loneliness. International Journal of Social Psychiatry, 66(6), 525-527. https://doi.org/10.1177/0020764020922269.

Czeisler, M. É., Marynak, K., Clarke, K. E. N., Salah, Z., Shakya, I., Thierry, J. M., et al. (2020). Delay or Avoidance of Medical Care Because of COVID-19-Related Concerns - United States, June 2020. MMWR. Morbidity and Mortality Weekly Report, 69(36), 1250-1257. https://doi.org/10.15585/mmwr. mm6936a4. 
Devlin, N., Parkin, D., \& Janssen, B. (2020). Methods for Analysing and Reporting EQ-5D Data. Methods for Analysing and Reporting EQ-5D Data. Springer Cham, Switzerland. https://doi.org/10.1007/978-3-03047622-9.

Economic and Social Research Institute. (2020). Quarterly Estimates of Household Disposable Income and Household Saving Ratio (Reference series): Estimates for Apr.-Jun. 2020. Cabinet Office. https://www. esri.cao.go.jp/en/sna/household/household top.html. Accessed 27 January 2020.

Fujikawa, A., Suzue, T., Jitsunari, F., \& Hirao, T. (2011). Evaluation of health-related quality of life using EQ5D in Takamatsu. Japan. Environmental Health and Preventive Medicine, 16, 25-35. https://doi.org/10. 1007/s12199-010-0162-1.

Hensher, M. (2020). Covid-19, unemployment, and health: time for deeper solutions? BMJ, m3687. doi: https://doi.org/10.1136/bmj.m3687

Hite, L. M., \& McDonald, K. S. (2020). Careers after COVID-19: challenges and changes. Human Resource Development International, 23(4), 427-437. https://doi.org/10.1080/13678868.2020.1779576.

Ikeda, S., Shiroiwa, T., Igarashi, A., Noto, S., Fukuda, T., Saito, S., \& Shimozuma, K. (2015). Developing a Japanese version of the EQ-5D-5L value set. J. Natl. Inst. Public Health [in Japanese], 64(1), 47-55.

Islam, N., Sharp, S. J., Chowell, G., Shabnam, S., Kawachi, I., Lacey, B., et al. (2020). Physical distancing interventions and incidence of coronavirus disease 2019: Natural experiment in 149 countries. The BMJ, 370, 2743. https://doi.org/10.1136/bmj.m2743.

Janssen, M. F., Szende, A., Cabases, J., Ramos-Goñi, J. M., Vilagut, G., König, H. H.. (2019). Population norms for the EQ-5D-3L: a cross-country analysis of population surveys for 20 countries, 20, 205-216. doi:https://doi.org/10.1007/s10198-018-0955-5

Kawohl, W., \& Nordt, C. (2020). COVID-19, unemployment and suicide. Lancet Psychiatry, 7(5), 389-390. https://doi.org/10.1192/bjp.2019.275.

Kucharski, A. J., Klepac, P., Conlan, A. J. K., Kissler, S. M., Tang, M. L., Fry, H., et al. (2020). Effectiveness of isolation, testing, contact tracing, and physical distancing on reducing transmission of SARS-CoV-2 in different settings: a mathematical modelling study. The Lancet. Infectious diseases. https://doi.org/10. 1016/S1473-3099(20)30457-6.

Madureira-Lima, J., Reeves, A., Clair, A., \& Stuckler, D. (2018). The Great Recession and inequalities in access to health care: A study of unemployment and unmet medical need in Europe in the economic crisis. International Journal of Epidemiology, 47(1), 58-68. https://doi.org/10.1093/ije/dyx193.

Mahmud, M. S., Talukder, M. U., \& Rahman, S. M. (2020). Does 'Fear of COVID-19' trigger future career anxiety? An empirical investigation considering depression from COVID-19 as a mediator. International Journal of Social Psychiatry. https://doi.org/10.1177/0020764020935488.

Margerison-Zilko, C., Goldman-Mellor, S., Falconi, A., \& Downing, J. (2016). Health impacts of the great recession: A critical review. Curr Epidemiol Rep, 3(1), 81-91.

McInerney, M., \& Mellor, J. M. (2012). Recessions and seniors' health, health behaviors, and healthcare use: Analysis of the Medicare Current Beneficiary Survey. Journal of Health Economics, 31(5), 744-751. https://doi.org/10.1016/j.jhealeco.2012.06.002.

Ministry of Health, Labour, and Welfare. (2019). Basic Survey on Wage Structure in 2019. https://www. mhlw.go.jp/toukei/itiran/roudou/chingin/kouzou/z2019/dl/07.pdf [in Japanese].

Ministry of Health, Labour, and Welfare. (2020). 【Press Conference】 The case of the coronavirus December 19, 2020. https://www.mhlw.go.jp/stf/seisakunitsuite/bunya/newpage_00032.html. Accessed 20 December 2020.

Ministry of Internal Affairs and Communications. (2020). Labor force survey: Monthly Results. Statistics Bureau. https://www.stat.go.jp/english/data/roudou/results/month/index.html. Accessed 20 October 2020.

Norström, F., Waenerlund, A. K., Lindholm, L., Nygren, R., Sahlén, K. G., \& Brydsten, A. (2019). Does unemployment contribute to poorer health-related quality of life among Swedish adults? BMC Public Health, 19, 457. https://doi.org/10.1186/s12889-019-6825-y.

Pieh, C., Budimir, S., Delgadillo, J., Barkham, M., Fontaine, J. R. J., \& Probst, T. (2020). Mental health during COVID-19 lockdown in the United Kingdom. Psychosomatic Medicine. https://doi.org/10.1097/ psy.0000000000000871.

Sánchez-Recio, R., Alonso, J. P., \& Aguilar-Palacio, I. (2020). The use of health care services in the Great Recession: evaluating inequalities in the Spanish context. Gaceta Sanitaria, 34(3), 245-252. https://doi. org/10.1016/j.gaceta.2019.10.009.

Smith, J. P. (2005). Consequences and predictors of new health events. In D. Wise (Ed.), Analyses in the economics of aging. Chicago: University of Chicago Press http://www.nber.org/papers/w10063.

Stekhoven, D. J., \& Bühlmann, P. (2012). Missforest-non-parametric missing value imputation for mixed-type data. Bioinformatics, 28(1), 112-118. https://doi.org/10.1093/bioinformatics/btr597. 
Tabuchi, T., Gallus, S., Shinozaki, T., Nakaya, T., Kunugita, N., \& Colwell, B. (2017). Heat-not-burn tobacco product use in Japan: its prevalence, predictors and perceived symptoms from exposure to secondhand heat-not-burn tobacco aerosol. Tobacco Control. https://doi.org/10.1136/tobaccocontrol-2017-053947.

Tabuchi, T., Shinozaki, T., Kunugita, N., Nakamura, M., \& Tsuji, I. (2019). Study profile: The Japan "society and new tobacco" internet survey (jastis): A longitudinal internet cohort study of heat-not-burn tobacco products, electronic cigarettes, and conventional tobacco products in Japan. Journal of Epidemiology, 29(11), 444-450. https://doi.org/10.2188/jea.JE20180116.

Tison, G., Avram, R., Kuhar, P., Abreau, S., Marcus, G., Pletcher, M., \& Olgin, J. (2020). Worldwide Effect of COVID-19 on Physical Activity: A Descriptive Study. Annals of Internal Medicine. https://doi.org/10. 7326/M20-2665.

Twenge, J. M., \& Joiner, T. E. (2020). U.S. Census Bureau-assessed prevalence of anxiety and depressive symptoms in 2019 and during the 2020 COVID-19 pandemic. Depression and Anxiety, 37(10), 954-956. https://doi.org/10.1002/da.23077.

US Bureau of Labor Statistics. (2020). Employment Situation Summary. https://www.bls.gov/news.release/ empsit.nr0.htm. Accessed 24 October 2020.

Ventura, L. (2020). Unemployment Rates Around the World 2020. Global Finance. https:/www.gfmag.com/ global-data/economic-data/worlds-unemployment-ratescom. Accessed 2 November 2020.

Xiong, J., Lipsitz, O., Nasri, F., Lui, L. M. W., Gill, H., Phan, L., et al. (2020). Impact of COVID-19 pandemic on mental health in the general population: A systematic review. Journal of Affective Disorders. https:// doi.org/10.1016/j.jad.2020.08.001.

Yang, Z., Busschbach, J., Liu, G., \& Luo, N. (2018). EQ-5D-5L norms for the urban Chinese population in China 11 Medical and Health Sciences 1117 Public Health and Health Services. Health and Quality of Life Outcomes, 16, 210. https://doi.org/10.1186/s12955-018-1036-2.

Publisher's Note Springer Nature remains neutral with regard to jurisdictional claims in published maps and institutional affiliations.

\section{Affiliations}

\section{Takaaki Ikeda $^{1,2} \cdot$ Ataru Igarashi $^{3} \cdot$ Satomi Odani $^{4} \cdot$ Masayasu Murakami $^{1}$. Takahiro Tabuchi $^{4}$}

1 Department of Health Policy Science, Graduate School of Medical Science, Yamagata University, Yamagata, Japan

2 Department of International and Community Oral Health, Tohoku University Graduate School of Dentistry, Miyagi, Japan

3 Yokohama City University School of Medicine, Kanagawa, Japan

4 Cancer Control Center, Osaka International Cancer Institute, Osaka, Japan 